\title{
ARTICLE
}

Received 30 Jan 2017 | Accepted 5 May 2017 | Published 19 Jun 2017

DOI: $10.1038 /$ ncomms15912 OPEN

\section{A bioinspired and biocompatible ortho-sulfiliminyl phenol synthesis}

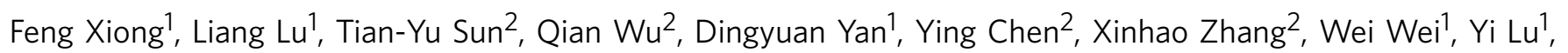
Wei-Yin Sun ${ }^{1}$, Jie Jack $\mathrm{Li}^{3} \&$ Jing Zhao ${ }^{1,2}$

Synthetic methods inspired by Nature often offer unique advantages including mild conditions and biocompatibility with aqueous media. Inspired by an ergothioneine biosynthesis protein EgtB, a mononuclear non-haem iron enzyme capable of catalysing the C-S bond formation and sulfoxidation, herein, we discovered a mild and metal-free $\mathrm{C}-\mathrm{H}$ sulfenylation/intramolecular rearrangement cascade reaction employing an internally oxidizing $\mathrm{O}-\mathrm{N}$ bond as a directing group. Our strategy accommodates a variety of oxyamines with good site selectivity and intrinsic oxidative properties. Combining an O-N bond with an $\mathrm{X}-\mathrm{S}$ bond generates a $\mathrm{C}-\mathrm{S}$ bond and an $\mathrm{S}=\mathrm{N}$ bond rapidly. The newly discovered cascade reaction showed excellent chemoselectivity and a wide substrate scope for both oxyamines and sulfenylation reagents. We demonstrated the biocompatibility of the $\mathrm{C}-\mathrm{S}$ bond coupling reaction by applying a coumarin-based fluorogenic probe in bacterial lysates. Finally, the C-S bond coupling reaction enabled the first fluorogenic formation of phospholipids, which self-assembled to fluorescent vesicles in situ.

\footnotetext{
${ }^{1}$ State Key Laboratory of Coordination Chemistry, Institute of Chemistry and BioMedical Sciences, School of Chemistry and Chemical Engineering, Nanjing University, Nanjing 210093, China. ${ }^{2}$ Guangdong Key Laboratory of Nano-Micro Material Research, School of Chemical Biology and Biotechnology, Peking University Shenzhen Graduate School, Shenzhen 518055, China. ${ }^{3}$ Department of Chemistry, University of San Francisco, 2130 Fulton Street, San Francisco, California 94117, USA. Correspondence and requests for materials should be addressed to J.Z. (email: jingzhao@nju.edu.cn).
} 
nzymatic C-S bond formation is a common process in biological system ${ }^{1-5}$. For example, ergothioneine is considered as a protectant against oxidative stress ${ }^{6,7}$. The key step in its biosynthesis pathway is the mononuclear non-haem iron enzyme EgtB-catalysed sulfenylation formation between $\gamma$-glutamyl cysteine and $N$ - $\alpha$-trimethyl histidine, involving a sulfur transfer step and an oxygen transfer step (Fig. 1a) ${ }^{8,9}$.

A variety of synthetic methods have been developed to construct the ortho-functionalized phenols which are highly useful in chemical industry $^{10}$, functional materials ${ }^{11}$ and medicines ${ }^{12-14}$. These methods mainly include three kinds of strategies: (a) rearrangement of aromatic O-X bonds ${ }^{15-20}$; (b) directing groupassisted ortho $\mathrm{C}-\mathrm{H}$ hydroxylation of arenes ${ }^{21-27}$; and (c) ortho $\mathrm{C}-\mathrm{H}$ functionalization of phenols ${ }^{28-32}$. Although these results have promoted the development of the phenol chemistry, the more efficient, economical and biocompatible methods are still in demand.

Inspired by the sulfur transferases and our previous successes in O-N bond-directed synthesis of ortho-functionalized phenol ${ }^{33-35}$, we envisioned that ortho-sulfiliminyl phenols could be obtained by combining a directing group containing an internally oxidizing $\mathrm{O}-\mathrm{N}$ bond with a sulfenylation reagent ${ }^{36,37}$. The desired sulfenylation reagent and oxidizing $\mathrm{X}-\mathrm{N}$ bond needs to accomplish the following two tasks (Fig. 1b): (i) sulfur transfer ${ }^{38,39}$. A well-chosen electrophilic sulfenylation reagent would facilitate the $\mathrm{N}$-sulfenylation of the X-N moiety and lead to the formation of an $\mathrm{N}-\mathrm{S}$ bond to produce intermediate $\mathbf{B}$; (ii) rearrangement. Pivotal progress was made by Maulide ${ }^{40,41}$, Procter $^{32,42}$, Yorimitsu ${ }^{31}$ and Peng ${ }^{43}$ who pioneered the directed, metal-free, redox-neutral and ortho-functionalization. These inspiring work suggested that when the substrate captured a suitable partner, the resulting intermediate may undergo a sigmatropic rearrangement and rearomatization to product $\mathbf{D}$, leading to the formation of a $\mathrm{C}-\mathrm{X}$ bond with concurrent $\mathrm{O}-\mathrm{X}$ bond cleavage. Herein, we report a rationally designed and metal-free coupling method to synthesize sulfilimines via an internal oxidantdirecting strategy for the cascade formation of $\mathrm{C}-\mathrm{S}$ and $\mathrm{S}=\mathrm{N}$ bonds at room temperature.

\section{Results}

Optimization of the reaction conditions. For direct coupling reactions, especially those catalysed by transition metals, a directing group typically escorts the metal catalyst towards the neighbouring ortho-position and dictates the site selectivity. Directing groups containing $\mathrm{N}-\mathrm{N}$ bond, $\mathrm{S}-\mathrm{N}$ bond or $\mathrm{O}-\mathrm{N}$ bond are redox versatile and could facilitate inter- or intramolecular cyclization ${ }^{44-47}$. At the outset of this study, compounds 1 with those bonds were firstly screened to couple with a thionating reagent $N$-ethylthiophthalimide $\mathbf{2 a}$ under previously reported metal catalysed conditions ${ }^{48-50}$ for similar reactions (Fig. 2a). Attempts on substrate $\mathbf{1}$ with $\mathrm{X}$ of $\mathrm{N}$ or $\mathrm{S}$ yielded no reaction. Gratifyingly, when $\mathrm{X}$ was replaced by $\mathrm{O}$, the resulting $\mathrm{N}$-phenoxyacetamide 1a concurrently constructed a C-S bond and an $\mathrm{S}=\mathrm{N}$ bond, giving the desired phenolic sulfilimine product 3 aa in $83 \%$ yield.

The $\mathrm{N}-\mathrm{H}$ bond in the O-NHAc moiety was found to be essential for the reaction as no reaction occurred when $\mathrm{N}-\mathrm{H}$ was methylated (Fig. 2a). The need for an electron-donating phenoxy group as well as an $\mathrm{N}-\mathrm{H}$ led us to suspect the existence of an ammonium ion as an essential intermediate in promoting the cascade reaction. Therefore, we removed the Rh catalyst and $\mathrm{N}_{2}$ protection from the reaction system and the reaction could occur smoothly under metal-free conditions. Next, different sulfenylation reagents were screened to explore the cascade strategy (Fig. 2b). Tolyl sulfides with different leaving groups on the $S$-atom such as chloride, tosyl and phthalimidoyl coupled with $N$-phenoxyacetamide 1a to afford 3af in 18, 33 and $85 \%$ yield, respectively. With benzenesulfenyl as the leaving group, however, no reaction took place, suggesting that disulfide remains intact during the course of the coupling reaction. As the coupling reaction was most likely mediated by a base, we tested various bases such as $\mathrm{Et}_{3} \mathrm{~N}$, DIPEA, DBU, $\mathrm{K}_{2} \mathrm{CO}_{3}, \mathrm{Na}_{2} \mathrm{CO}_{3}, \mathrm{NaOAc}$ and $\mathrm{CsOAc}$, where $\mathrm{CsOAc}$ gave the highest yield. Switching the reaction solvent to methanol and using an air atmosphere, the yield of the phenol product 3aa was further improved to $92 \%$ (Supplementary Information, Supplementary Table 6).

Substrate scope of the reaction. To probe the scope of the transition metal-free cascade $\mathrm{C}-\mathrm{S}$ and $\mathrm{S}=\mathrm{N}$ bond formation, we examined a series of oxyamide substrates (Table 1). Replacing the acetyl group with a bulkier pivaloyl or a benzoyl group only slightly decreased the yield to $80 \%$ (3ba) and $83 \%$ (3ca), respectively. It is worth noting that the sulfilimine substitution occurred exclusively at the ortho-position of the phenoxyamide moiety instead of the benzamide moiety (3ca), which indicated the stronger directing ability of the oxyamide group for sulfenylation. Substitutions on the phenoxy side of 1 had little impact on the yield. Electron-donating groups (3da, 3ea, 3ia, 3la), electron-withdrawing groups (3ha), as well as halogen groups (3fa, 3ga) were well tolerated, which afforded substituted sulfilimines in $85 \%$ to $92 \%$ yield. The $\mathrm{C}-\mathrm{S}$ bond formation proceeded exclusively at the site ortho to the acetylaminoxy group. Therefore, for substrate 1 with two different ortho-sites, two regioisomers with ratio almost $1: 1$ were produced (3ja:3ja', 3ka:3ka', 3ma:3ma', 3na:3na'). Fusion of a benzene ring as in the substrate of naphthalene did not affect the reaction yield but resulted in high regioselectivity, which only functionalized the ortho $\mathrm{C}-\mathrm{H}$ at $\mathrm{C}-1$ position, resulting in a 2 -naphthol derivative (3oa).

Under optimal conditions, we explored the substrate scope for $N$-substituted phthalimides (Table 2). The reaction proceeded smoothly for both aliphatic and aromatic thiophthalimides. Aliphatic groups including trifluoromethyl, linear alkyl and cyclic alkyl gave high yields (3ab-3ad, 76-92\%). For aromatic thiophthalimides, substitutions on the phenyl ring increased the reaction yield (3af-3aj $>\mathbf{3 a e}$ ). The reaction proceeded well with either electron-donating groups or halogen-containing substrates.

Synthetic application. To further explore the applicability of our method as a useful tool in chemical biology, we conducted the reaction in PBS buffer in air. Gratifyingly, the reaction proceeded well. When the ratio of DMSO to $\mathrm{pH} 7.41 \times$ PBS buffer was $1: 19,81 \%$ yield was obtained (Fig. 3a, entry 1). Because of the excellent chemoselectivity under the mild aqueous conditions, we tested the compatibility of the $\mathrm{C}-\mathrm{S}$ bond coupling reaction with various biomolecules, such as amino acids and proteins. The addition of a stoichiometric amount of amino acids or proteins in standard aqueous conditions did not significantly affect the reaction (Fig. 3a, entry $2 \sim 5$ ). Bacterial cell lysates that contained various endogenous biomolecules were also tested and gave product 3aa in $73 \%$ yield (Fig. 3a, entry 6). When we started from a non-fluorescent coumarin substrate (1p) to react with 2 a under such biomimetic conditions, a fluorescent turn-on process was observed. The fluorescent product 3pa $\left(\lambda_{\mathrm{ex} / \mathrm{em}}=360 / 450 \mathrm{~nm}\right)$ was obtained in $80 \%$ yield (Fig. 3 b).

Finally, we further applied the $\mathrm{C}-\mathrm{S}$ bond coupling reaction to the first fluorogenic formation of phospholipids. We designed a non-fluorescent coumarin-functionalized analogue of the lysolipid 1-palmitoyl-sn-glycero-3-phosphocholine $\mathbf{1 q}$ and a linear alkyl sulfenylation reagent $\mathbf{2 k}$. Phospholipids, which are the major 
a Enzymatic oxidative C-S bond formation and sulfoxidation

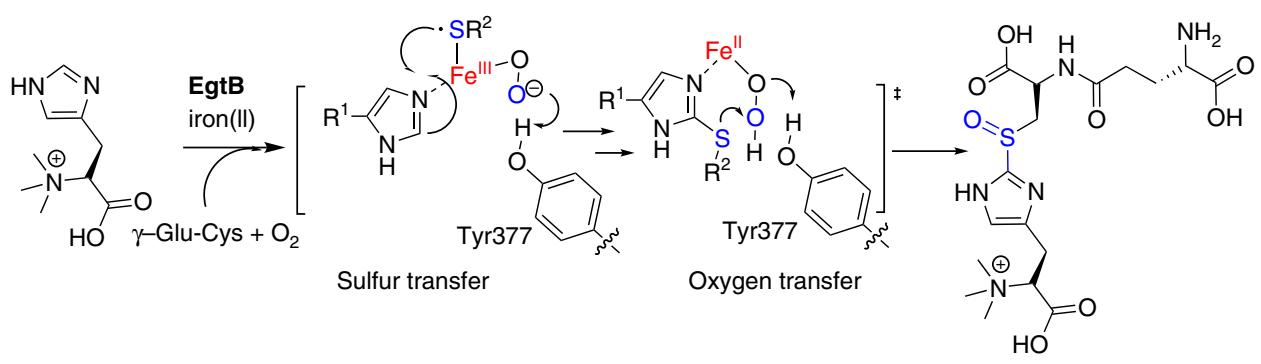

b

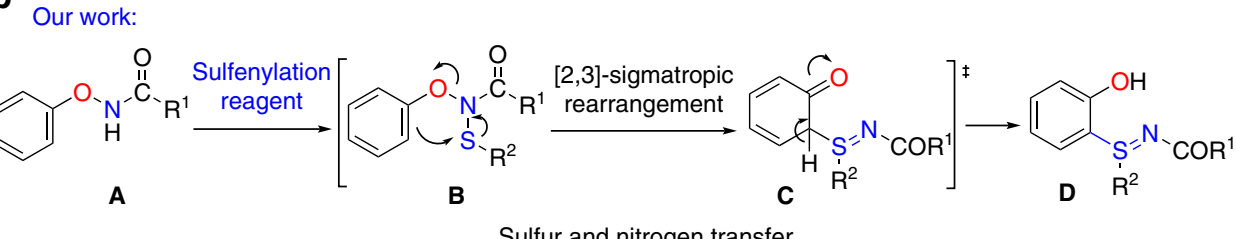

Figure 1 | Strategy for the formation of ortho-sulfiliminyl phenol derivatives. (a) The mononuclear non-haem iron enzyme EgtB-catalysed sulfenylation formation between $\gamma$-glutamyl cysteine and $\mathrm{N}$ - $\alpha$-trimethyl histidine. (b) A metal-free approach to ortho-sulfiliminyl phenol via the $\mathrm{C}-\mathrm{H}$ sulfenylation/intramolecular rearrangement cascade reaction.

a<smiles>[R]N([X]c1ccccc1)C(C)=O</smiles>

b<smiles>[Y]c1ccccc1S(=N)CC</smiles>

$X=N H, R=H: N . R$. $X=S, R=H: N . R$.

$X=O, R=M e: N . R$.

$X=O, R=H: 3 a a, 83 \%$<smiles>NOc1ccccc1</smiles>

1a<smiles>[R]Sc1ccc(C)cc1</smiles>

2

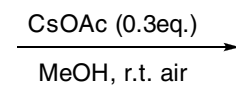<smiles>Cc1ccc(S(=N)c2ccccc2O)cc1</smiles>

$\mathrm{R}=$

$18 \%$

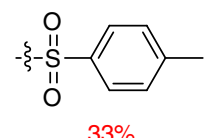

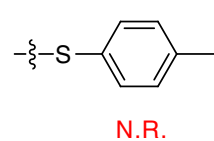

N.R.

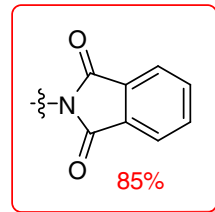

Figure 2 | Screening of the $\mathbf{X}-\mathbf{N}$ functional groups and thiolating reagents. (a) Screening of the multifunctional X-N functional group; reaction conditions: $0.2 \mathrm{mmol}$ substrate $\mathbf{1}, \mathrm{N}$-ethylthiophthalimides (1.2 equiv.), $\left[\mathrm{Cp}^{\star} \mathrm{RhCl}_{2}\right]_{2}(5 \mathrm{~mol} \%)$ and $\mathrm{CsOAc}\left(0.3\right.$ equiv.) in $\mathrm{CH}_{3} \mathrm{CN}(1 \mathrm{ml})$ at room temperature under $\mathrm{N}_{2}$ for $15 \mathrm{~h}$. (b) Screening of different thiolating reagents with $\mathrm{N}$-phenoxyamides. Reaction conditions: $0.2 \mathrm{mmol}$ substrate $\mathbf{1 a}, \mathbf{2}$ (1.2 equiv.) and $\mathrm{CsOAc}$ ( 0.3 equiv.) in $\mathrm{MeOH}(1 \mathrm{ml})$ at room temperature for $15 \mathrm{~h}$. Yields are those of isolated products. N.R. $=$ No reaction.

component of cell membranes, have many important applications such as drug delivery ${ }^{51,52}$, construction of micro-reactors ${ }^{53}$ and study of protein-membrane interactions $s^{54}$. Pioneered by Devaraj et al., it has been of increasing significance to develop methods for the de novo synthesis and assembly of phospholipid membranes ${ }^{55-58}$. To apply our mild C-S bond coupling reaction to the formation of the lipid vesicle under optimal conditions, we simply mixed compounds $\mathbf{1 q}$ and $\mathbf{2 k}$ in $0.1 \mathrm{M}$ PBS buffer at $\mathrm{pH} 7.4$ and sonicated the mixture at room temperature for $1 \mathrm{~h}$. Blue fluorescent lipid vesicles were observed by the fluorescence microscopy after $3 \mathrm{~h}$ at $37^{\circ} \mathrm{C}$ (Fig. 4c). We confirmed these vesicles were lipid membrane structures by staining with the membrane- staining dye $1,1^{\prime}$-dioctadecyl-3,3,3',3'-tetramethylindocarbocyanine perchlorate (DiI), and the orange red fluorescent vesicles were observed, suggesting that fluorescent phospholipid 3qk vesicles are lipid membranes (Fig. 4c).

Mechanistic investigation. A combined experimental/computational study was conducted to investigate the reaction mechanism. The cross-over experiment was carried out using a 1:1 mixture of $N$-phenoxyacetamide $1 \mathbf{a}$ and its analogue $1 \mathbf{a}-d_{8}$ under the standard conditions, only the intramolecular rearrangement products $\mathbf{3} \mathbf{a}$ a and $\mathbf{3 a a}-d_{7}$ were obtained (Supplementary 
Table 1 | Substrate scope of aryloxyamides ${ }^{\star}$.

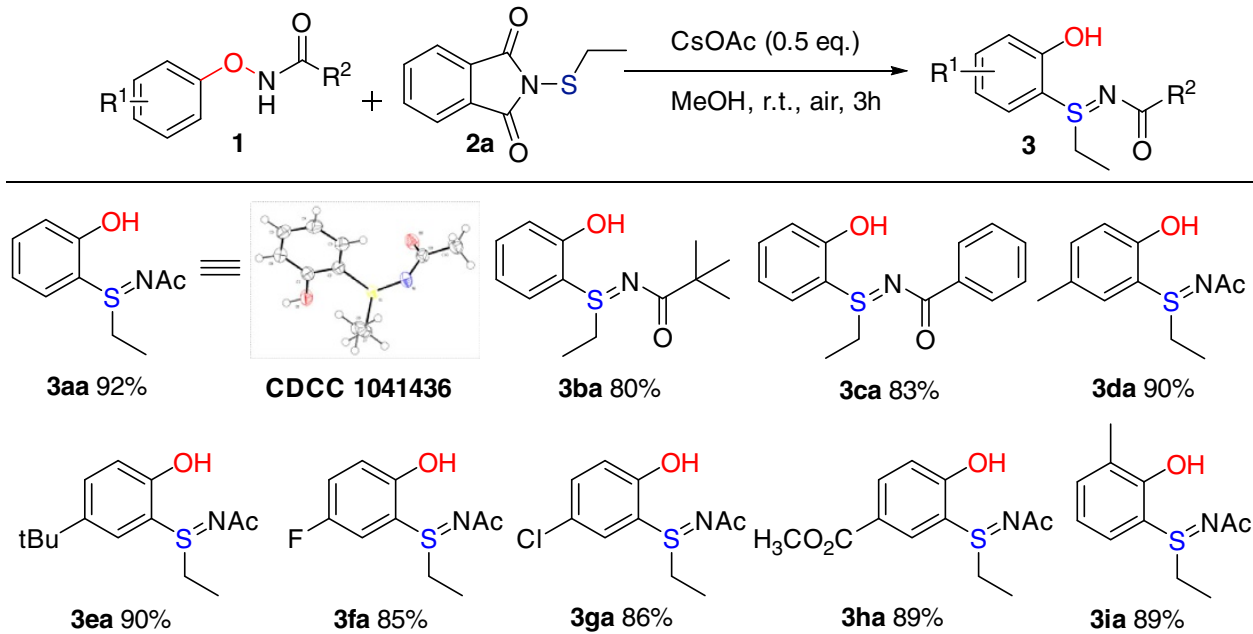<smiles>CCSS(=NC(C)=O)c1c(C)cccc1S(CC)=N[C+](C)(C)C</smiles>

3ja:3ja' 89\% (1.1:1)<smiles>CCS(=NC(=O)c1ccc(Cl)cc1O)c1ccc(Cl)cc1O</smiles>

3ma:3ma' 85\% (1:1)<smiles>CCS(=NC(C)=O)c1ccc(F)cc1O</smiles>

3ka:3ka' 84\% (1.05:1)<smiles>CCS(=NC(C)(C)C)c1cc(OC)ccc1O</smiles>

3la $88 \%$<smiles>CCS(=N[C+]=[Co])c1cccc(O)c1S(CC)=NC(C)C</smiles>

3na:3na' 86\% (1:1)<smiles>CCS(=NC)c1c(O)ccc2ccccc12</smiles>

3oa $90 \%$

${ }^{\star}$ Reaction conditions: $0.2 \mathrm{mmol}$ oxyamide, $\mathrm{N}$-ethylthiophthalimides ( 1.2 equiv.) and $\mathrm{CsOAc}(0.5$ equiv.) in $\mathrm{MeOH}(1 \mathrm{ml})$ at room temperature for $3 \mathrm{~h}$. Yields are those of isolated products.

\section{Table 2 | Substrate scope of $\mathbf{N}$-substituted thiophthalimides ${ }^{\star}$.}

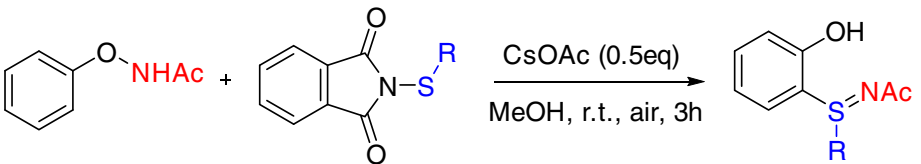

1 a

2

3

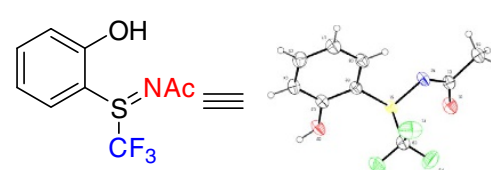

3ab $92 \%$<smiles>CC(C)=[W]=NS(c1ccccc1)=S(c1ccc(C)cc1)c1ccccc1O</smiles>

3af $85 \%$
CCDC 983618<smiles>COc1ccc(S(=NC(=O)c2ccccc2O)c2ccccc2)cc1</smiles>

3ag 80\%<smiles>CCCC(C)=[SH](=O)c1ccccc1O</smiles>

3ac $85 \%$<smiles>CN=S(c1ccc(F)cc1)c1ccccc1O</smiles>

3ah 75\%<smiles>O=S(=O)(c1ccccc1O)C1CCCCC1</smiles>

3ad $76 \%$<smiles>CN=Cc1ccccc1O</smiles><smiles>CS(=O)c1ccc(Cl)cc1</smiles>

3ai $70 \%$<smiles>CN(c1ccccc1)S(=O)c1ccccc1O</smiles>

3ae $67 \%$

${ }^{*}$ Reaction conditions: $0.2 \mathrm{mmol} \mathbf{1 a}, \mathrm{N}$-substituted thiophthalimides (1.2 equiv.) and $\mathrm{CsOAc}(0.5$ equiv.) in $\mathrm{MeOH}(1 \mathrm{ml})$ at room temperature for $3 \mathrm{~h}$. Yields are those of isolated products. 
a

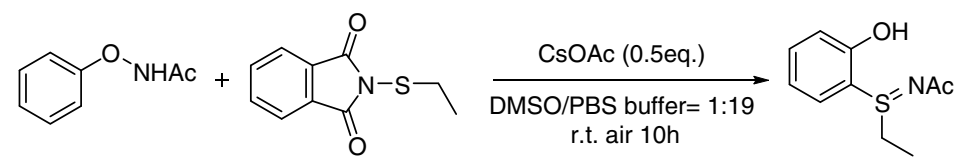

$1 a$

2a

3aa

\begin{tabular}{ccccc} 
Entry & Conditions & Time & Conversion & Yield \\
\hline 1 & $5 \%$ DMSO, 95\% PH 7.4 1X PBS & $10 \mathrm{~h}$ & $>95 \%$ & $81 \%$ \\
2 & Entry 1, 1 equiv L-tyrosine & $10 \mathrm{~h}$ & $>95 \%$ & $75 \%$ \\
3 & Entry 1, 1 equiv L-cysteine & $10 \mathrm{~h}$ & $>95 \%$ & $76 \%$ \\
4 & Entry 1, 1 equiv L-methionine & $10 \mathrm{~h}$ & $>95 \%$ & $78 \%$ \\
5 & Entry 1, 10 $\mathrm{mg} \mathrm{ml}^{-1}$ bovine serum albumin & $10 \mathrm{~h}$ & $>95 \%$ & $76 \%$ \\
6 & Entry 1, $2 \mathrm{mg} \mathrm{ml}^{-1}$ bacterial cell lysates & $10 \mathrm{~h}$ & $>95 \%$ & $73 \%$
\end{tabular}

b

(urn off

$1 \mathrm{p}$

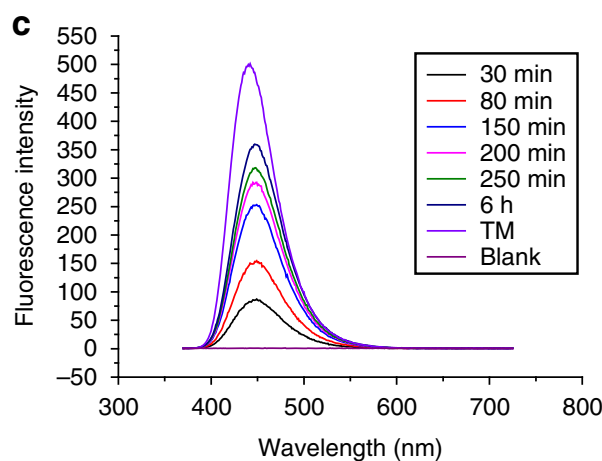

Turn on

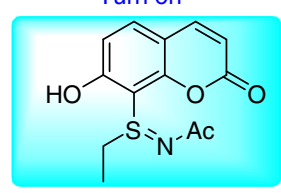

3pa

d

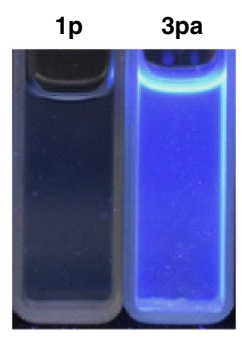

Figure 3 | Application of the C-S bond coupling reaction in biocompatible conditions. (a) C-S bond coupling reaction in aqueous conditions and in the presence of biomolecules. Conditions: $\mathbf{1 a}(0.075 \mathrm{mmol}), \mathbf{2 a}(0.09 \mathrm{mmol}), \mathrm{CsOAc}(0.5$ equiv.), DMSO/PBS buffer $=1: 19$ ( $5 \mathrm{ml})$; the yield was determined by ${ }^{1} \mathrm{H}$ NMR spectroscopy using 1,4-dimethoxybenzene as an internal standard. The temperature was RT. (b) Reaction of $\mathbf{1 p}$ with $\mathbf{2 a}$ in aqueous conditions. Conditions: 1p $(0.2 \mathrm{mmol}), \mathbf{2 a}(0.24 \mathrm{mmol}), \mathrm{CsOAc}(0.5$ equiv.), DMSO/PBS buffer =1:19 (10 ml); isolated yield. The temperature was RT. (c) Fluorescence spectra of reaction $\mathbf{b}$ in aqueous conditions. (d) Photograph showing the visual fluorescence of $\mathbf{1 p}$ and $\mathbf{3 p a}$ under a $365 \mathrm{~nm}$ ultraviolet lamp.

Fig. 36a), suggesting an intramolecular process. The cross-over experiment between 1c, $1 \mathbf{d}$ and 2 a confirmed this conclusion (Supplementary Fig. 36b). To further probe the reaction mechanism, the potential energy surface of the proposed pathway was calculated with density functional theory. The computational results suggested that the reaction proceeds through $N$-sulfenylation, [2, 3] sigmatropic rearrangement and aromatization (Supplementary Fig. 37a).

In summary, we have developed a bioinspired strategy for the synthesis of ortho-sulfiliminyl phenols by internal oxidation-induced sulfur transfer under mild conditions. This efficient method enabled the simultaneous construction of C-S and $\mathrm{S}=\mathrm{N}$ bonds. Thanks to the mild nature and good functionality tolerance of the reaction conditions, a wide range of oxyacetamides was converted into the corresponding phenols. For the sulfur donors, not only trifluoromethylthio group $\left(\mathrm{CF}_{3} \mathrm{~S}-\right)$ but also a variety of sulfur-containing groups were able to participate in $\mathrm{C}-\mathrm{H}$ sulfenylation. The sulfur donors included $N$-substituted thiophthalimides with $S$-substituted aromatic and aliphatic groups. Moreover, the method utilized the leaving acetamide moiety of the internal oxidant/directing oxyacetamide group to construct a sulfilimine functional group. Our method was successfully applied to the in situ formation of fluorogenic phospholipid membranes. To the best of our knowledge, this is the first fluorogenic phospholipid membranes formation. Further applications of the fluorogenic phospholipid membranes are under investigation and will be reported in due course.

\section{Methods}

Materials. For NMR spectra of compounds in this manuscript, see Supplementary Figs 1-32. For the crystallographic data of compound 3aa and 3ab, see Supplementary Figs 33 and 34 and Supplementary Tables 1-5. For the representative experimental procedures and analytic data of compounds synthesized, see Supplementary Methods.

General procedure of $\mathbf{C}-\mathbf{S}$ bond coupling reaction. Aryloxyamide (1) $(0.2 \mathrm{mmol}), \mathrm{N}$-substituted thiophthalimides (2) $(0.24 \mathrm{mmol})$ and $\mathrm{CsOAc}$ $(0.06 \mathrm{mmol}$ or $0.10 \mathrm{~mol})$ were weighed into a $10 \mathrm{ml}$ pressure tube, to which was added $\mathrm{MeOH}(1 \mathrm{ml})$. The reaction vessel was stirred at room temperature for $3 \mathrm{~h}$ in air. Then the mixture was concentrated under vacuum and the residue was purified by column chromatography on silica gel with a gradient eluent of petroleum ether and ethyl acetate to afford the corresponding product.

In situ self-assembly of fluorescent vesicles. An aliquot of $10.0 \mu \mathrm{l}$ of a $4 \mathrm{mM}$ coumarin-functionalized analogue of the lysolipid 1-palmitoyl-sn-glycero-3-phosphocholine 1q solution in $100 \mathrm{mM}$ PBS buffer $\mathrm{pH} 7.4$ was added to $2.0 \mu \mathrm{l}$ of a $20 \mathrm{mM}$ solution of sulfenylation reagent $2 \mathbf{k}$ in $\mathrm{CHCl}_{3}$. Then, $28 \mu \mathrm{l}$ of a $100 \mathrm{mM}$ PBS buffer $\mathrm{pH} 7.4$ solution was added, and the mixture was sonicated at room temperature (RT) for $1 \mathrm{~h}$. after $3 \mathrm{~h}$ standing at $37^{\circ} \mathrm{C}$, stained with membrane-staining dye DiI, 10 min later, the corresponding mixture was observed by fluorescence microscopy. 
a

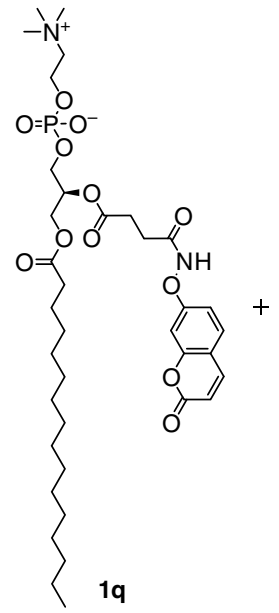

b

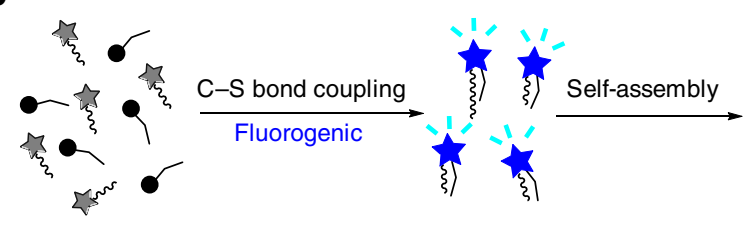

C

Bright field

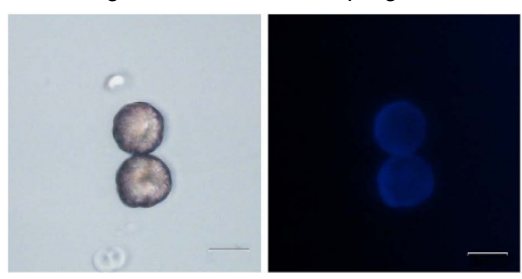

C-S bond

\begin{abstract}
coupling reaction
\end{abstract}

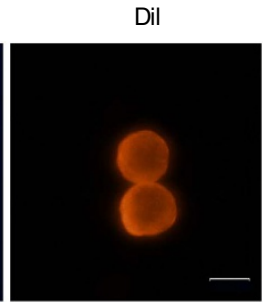

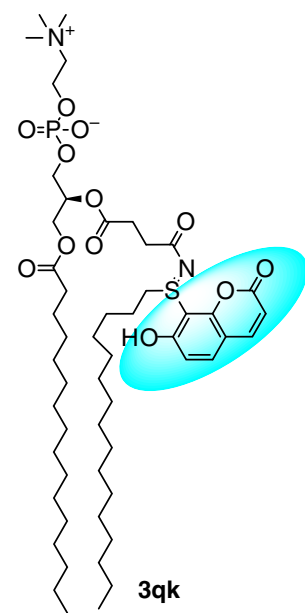

$3 q k$

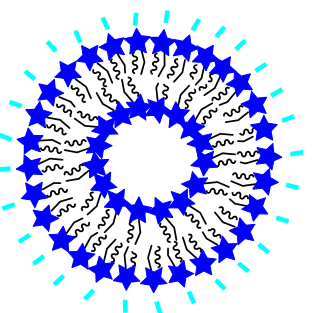

Merge

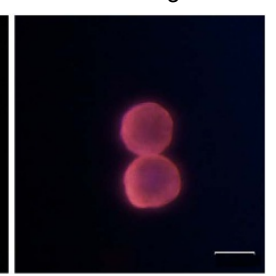

Figure 4 | Synthesis of fluorogenic phospholipids by C-S bond coupling reaction. (a) Reaction conditions: $\mathbf{1 q}$ ( $4 \mathrm{mM}$ in PBS buffer, $10 \mu \mathrm{l}$ ) and $\mathbf{2 k}$ (20 $\mathrm{mM}$ in $\left.\mathrm{CHCl}_{3}, 2 \mu \mathrm{l}\right)$ in PBS buffer PH $7.4(28 \mu \mathrm{l})$ was sonicated at RT for $1 \mathrm{~h}$; (b) Model of spontaneous fluorescent vesicle assembly induced by $\mathrm{C}-\mathrm{S}$ bond coupling reaction; (c) Fluorescent microscopic images of phospholipid vesicles. Conditions: 1q ( $4 \mathrm{mM}$ in PBS buffer, $10 \mu \mathrm{l})$ and $\mathbf{2 k}\left(20 \mathrm{mM}\right.$ in $\left.\mathrm{CHCl}_{3}, 2 \mu \mathrm{l}\right)$ in PBS buffer PH $7.4(28 \mu \mathrm{l})$ was sonicated at RT for $1 \mathrm{~h}$, after $3 \mathrm{~h}$ standing at $37^{\circ} \mathrm{C}$, stained with Dil before being imaged on the fluorescence microscopy. Scale bar, $20 \mu \mathrm{M}$.

Data availability. The X-ray crystallographic coordinates for structures reported in this study have been deposited at the Cambridge Crystallographic Data Centre (CCDC), under deposition numbers CCDC1041436 and CCDC983618. These data can be obtained free of charge from The Cambridge Crystallographic Data Centre via www.ccdc.cam.ac.uk/data_request/cif. The authors declare that all other data supporting the findings of this study are available within the article and Supplementary Information files, and also are available from the corresponding author upon reasonable request.

\section{References}

1. Li, B. et al. Structure and mechanism of the lantibiotic cyclase involved in nisin biosynthesis. Science 311, 1464-1467 (2006).

2. Sasaki, E. et al. Co-opting sulphur-carrier proteins from primary metabolic pathways for 2-thiosugar biosynthesis. Nature 510, 427-431 (2014).

3. Chatterjee, A. et al. Saccharomyces cerevisiae THI4p is a suicide thiamine thiazole synthase. Nature 478, 542-546 (2011).

4. Berkovitch, F., Nicolet, Y., Wan, J. T., Jarrett, J. T. \& Drennan, C. L. Crystal structure of biotin synthase, an S-adenosylmethionine-dependent radical enzyme. Science 303, 76-79 (2004).

5. Fontecave, M., Ollagnier-de-Choudens, S. \& Mulliez, E. Biological radical sulfur insertion reactions. Chem. Rev. 103, 2149-2166 (2003).

6. Jacob, C. A scent of therapy: pharmacological implications of natural products containing redox-active sulfur atoms. Nat. Prod. Rep. 23, 851-863 (2006).

7. Bello, M. H., Barrera-Perez, V., Morin, D. \& Epstein, L. The neurospora crassa mutant Nc $\Delta$ Egt-1 identifies an ergothioneine biosynthetic gene and demonstrates that ergothioneine enhances conidial survival and protects against peroxide toxicity during conidial germination. Fungal. Genet. Biol. 49, $160-172$ (2012).
8. Goncharenko, K. V., Vit, A., Blankenfeldt, W. \& Seebeck, F. P. Structure of the sulfoxide synthase EgtB from the ergothioneine biosynthetic pathway. Angew. Chem. Int. Ed. 54, 2821-2824 (2015).

9. Song, H., Leninger, M., Lee, N. \& Liu, P. Regioselectivity of the oxidative C-S bond formation in ergothioneine and ovothiol biosyntheses. Org. Lett. 15, 4854-4857 (2013).

10. Fiegel, H. et al. Phenol Derivatives in Ullmann's Encyclopedia of Industrial Chemistry (Wiley-VCH, 2002).

11. Kim, N. G., Shin, C. H., Lee, M. H. \& Do, Y. Four-coordinate boron compounds derived from 2-(2-pyridyl)phenol ligand as novel hole-blocking materials for phosphorescent OLEDs. J. Organomet. Chem. 694, 1922-1928 (2009).

12. Cheng, C. et al. Marinopyrrole derivatives as potential antibiotic agents against methicillin-resistant Staphylococcus aureus (II). Mar. Drugs 11, 2927-2948 (2013).

13. Zwaagstra, M. E. et al. Synthesis and structure-activity relationships of carboxylated chalcones:a novel series of CysLT1 (LTD4) receptor antagonists. J. Med. Chem. 40, 1075-1089 (1997).

14. Charest, M. G., Lerner, C. D., Brubaker, J. D., Siegel, D. R. \& Myers, A. G. A convergent enantioselective route to structurally diverse 6-deoxytetracycline antibiotics. Science 308, 395-398 (2005).

15. Berchel, M., Salaun, J. Y., Couthon-Gourves, H., Haelters, J. P. \& Jaffres, P. A. An unexpected base-induced [1,4]-phospho-Fries rearrangement. Dalton Trans. 39, 11314-11316 (2010).

16. Dyke, A. M. et al. Decoupling deprotonation from metalation: thia-fries rearrangement. Angew. Chem. Int. Ed. 47, 5067-5070 (2008). 
17. Hua, Y., Asgari, P., Avullala, T. \& Jeon, J. Catalytic reductive ortho-C-H silylation of phenols with traceless, versatile acetal directing groups and synthetic applications of dioxasilines. J. Am. Chem. Soc. 138, 7982-7991 (2016).

18. Huang, C., Chattopadhyay, B. \& Gevorgyan, V. Silanol: a traceless directing group for Pd-catalyzed o-alkenylation of phenols. J. Am. Chem. Soc 133, 12406-12409 (2011)

19. Wang, Y. \& Gevorgyan, V. General method for the synthesis of salicylic acids from phenols through palladium-catalyzed silanol-directed C-H carboxylation. Angew. Chem. Int. Ed. 54, 2255-2259 (2015).

20. Zhao, Z., Messinger, J., Schon, U., Wartchow, R. \& Butenschon, H. Unanticipated formation of ortho-sulfone substituted phenols by anionic thia-Fries rearrangement of (aryl triflate)tricarbonylchromium complexes. Chem. Commun. 42, 3007-3009 (2006).

21. Shan, G., Yang, X., Ma, L. \& Rao, Y. Pd-catalyzed C-H oxygenation with TFA/TFAA: expedient access to oxygen-containing heterocycles and late-stage drug modification. Angew. Chem. Int. Ed. 51, 13070-13074 (2012).

22. Sun, X., Sun, Y., Zhang, C. \& Rao, Y. Room-temperature Pd-catalyzed C-H chlorination by weak coordination: one-pot synthesis of 2-chlorophenols with excellent regioselectivity. Chem. Commun. 50, 1262-1264 (2014).

23. Yang, Y., Lin, Y. \& Rao, Y. Ruthenium(II)-catalyzed synthesis of hydroxylated arenes with ester as an effective directing group. Org. Lett. 14, 2874-2877 (2012).

24. Yang, X., Shan, G. \& Rao, Y. Synthesis of 2-aminophenols and heterocycles by Ru-catalyzed C-H mono- and dihydroxylation. Org. Lett. 15, 2334-2337 (2013).

25. Yan, Y. et al. $\mathrm{PdCl}_{2}$ and $N$-hydroxyphthalimide co-catalyzed $\mathrm{C}_{(\mathrm{sp} 2)}-\mathrm{H}$ hydroxylation by dioxygen activation. Angew. Chem. Int. Ed. 52, 5827-5831 (2013).

26. Mo, F., Trzepkowski, L. J. \& Dong, G. Synthesis of ortho-acylphenols through the palladium-catalyzed ketone-directed hydroxylation of arenes. Angew. Chem. Int. Ed. 51, 13075-13079 (2012).

27. Zhang, Y. H. \& Yu, J. Q. Pd(II)-catalyzed hydroxylation of arenes with 1 atm of $\mathrm{O}_{2}$ or air. J. Am. Chem. Soc. 131, 14654-14655 (2009).

28. Tian, H., Zhu, C., Yang, H. \& Fu, H. Iron or boron-catalyzed C-H arylthiation of substituted phenols at room temperature. Chem. Commun. 50, 8875-8877 (2014).

29. Bedford, R. B., Coles, S. J., Hursthouse, M. B. \& Limmert, M. E. The catalytic intermolecular orthoarylation of phenols. Angew. Chem. Int. Ed. 42, 112-114 (2003).

30. Dorta, R. \& Togni, A. Addition of the ortho-C-H bonds of phenol across an olefin catalysed by a chiral iridium (I) diphosphine complex. Chem. Commun. 39, 760-761 (2003).

31. Yanagi, T. et al. Metal-Free approach to biaryls from phenols and aryl sulfoxides by temporarily sulfur-tethered regioselective $\mathrm{C}-\mathrm{H} / \mathrm{C}-\mathrm{H}$ coupling. J. Am. Chem. Soc. 138, 14582-14585 (2016)

32. Shrives, H. J., Fernandez-Salas, J. A., Hedtke, C., Pulis, A. P. \& Procter, D. J Regioselective synthesis of C3 alkylated and arylated benzothiophenes. Nat. Commun. 8, 14801 (2017)

33. Chen, Y. et al. A multitasking functional group leads to structural diversity using designer C-H activation reaction cascades. Nat. Commun. 5, 4610 (2014).

34. $\mathrm{Wu}, \mathrm{Q}$. et al. Unified synthesis of mono/bis-arylated phenols via RhIII-catalyzed dehydrogenative coupling. Chem. Sci. 8, 169-173 (2017).

35. Wu, Q. et al. A redox-neutral catechol synthesis. Nat. Commun. 8, 14227 (2017).

36. Arisawa, M., Suzuki, T., Ishikawa, T. \& Yamaguchi, M. Rhodium-catalyzed substitution reaction of aryl fluorides with disulfides: $p$-orientation in the polyarylthiolation of polyfluorobenzenes. J. Am. Chem. Soc. 130, 12214-12215 (2008).

37. Yoshida, S. et al. A mild and facile synthesis of aryl and alkenyl sulfides via copper-catalyzed deborylthiolation of organoborons with thiosulfonates. Chem. Commun. 51, 16613-16616 (2015).

38. Denmark, S. E., Hartmann, E., Kornfilt, D. J. \& Wang, H. Mechanistic, crystallographic, and computational studies on the catalytic, enantioselective sulfenofunctionalization of alkenes. Nat. Chem. 6, 1056-1064 (2014).

39. Xu, C., Ma, B. \& Shen, Q. N-trifluoromethylthiosaccharin: an easily accessible, shelf-stable, broadly applicable trifluoromethylthiolating reagent. Angew. Chem. Int. Ed. 53, 9316-9320 (2014).

40. Huang, X., Patil, M., Fares, C., Thiel, W. \& Maulide, N. Sulfur(IV)-mediated transformations: from ylide transfer to metal-free arylation of carbonyl compounds. J. Am. Chem. Soc. 135, 7312-7323 (2013).

41. Peng, B., Geerdink, D., Fares, C. \& Maulide, N. Chemoselective intermolecular alpha-arylation of amides. Angew. Chem. Int. Ed. 53, 5462-5466 (2014)

42. Fernandez-Salas, J. A., Eberhart, A. J. \& Procter, D. J. Metal-Free CH-CH-type cross-coupling of arenes and alkynes directed by a multifunctional sulfoxide group. J. Am. Chem. Soc. 138, 790-793 (2016).

43. Shang, L. et al. Redox-neutral alpha-arylation of alkyl nitriles with aryl sulfoxides: a rapid electrophilic rearrangement. J. Am. Chem. Soc. 139, 4211-4217 (2017)

44. Hu, F. et al. Rhodium(III)-catalyzed ortho alkenylation of $N$ phenoxyacetamides with $\mathrm{N}$-tosylhydrazones or diazoesters through $\mathrm{C}-\mathrm{H}$ activation. Angew. Chem. Int. Ed. 53, 1364-1367 (2014).

45. Li, B., Lan, J., Wu, D. \& You, J. Rhodium(III)-catalyzed ortho-heteroarylation of phenols through internal oxidative $\mathrm{C}-\mathrm{H}$ activation: rapid screening of single-molecular white-light-emitting materials. Angew. Chem. Int. Ed. 54, 14008-14012 (2015)

46. Liu, G., Shen, Y., Zhou, Z. \& Lu, X. Rhodium(III)-catalyzed redox-neutral coupling of $\mathrm{N}$-phenoxyacetamides and alkynes with tunable selectivity. Angew. Chem. Int. Ed. 52, 6033-6037 (2013).

47. Zhang, H. et al. Rhodium(III)-catalyzed transannulation of cyclopropenes with $\mathrm{N}$-phenoxyacetamides through $\mathrm{C}-\mathrm{H}$ activation. Angew. Chem. Int. Ed. 53, 13234-132348 (2014).

48. Guimond, N., Gorelsky, S. I. \& Fagnou, K. Rhodium(III)-catalyzed heterocycle synthesis using an internal oxidant: improved reactivity and mechanistic studies. J. Am. Chem. Soc. 133, 6449-6457 (2011).

49. Rakshit, S., Grohmann, C., Besset, T. \& Glorius, F. Rh(III)-catalyzed directed $\mathrm{C}-\mathrm{H}$ olefination using an oxidizing directing group: mild, efficient, and versatile. J. Am. Chem. Soc. 133, 2350-2353 (2011).

50. Guimond, N., Gorelsky, C. \& Fagnou, K. Rhodium(III)-catalyzed isoquinolone synthesis: the N-O bond as a handle for $\mathrm{C}-\mathrm{N}$ bond formation and catalyst turnover. J. Am. Chem. Soc. 132, 6908-6909 (2010)

51. Soussan, E., Cassel, S., Blanzat, M. \& Rico-Lattes, I. Drug delivery by soft matter: matrix and vesicular carriers. Angew. Chem. Int. Ed. 48, 274-288 (2009).

52. Kraft, J. C., Freeling, J. P., Wang, Z. Y. \& HO, R. J. Y. Emerging research and clinical development trends of liposome and lipid nanoparticle drug delivery systems. J. Pharm. Sic. 103, 29-52 (2014).

53. Vriezema, D. M. et al. Self-Assembled nanoreactors. Chem. Rev. 105, 1445-1490 (2005).

54. Rudd, A. K., Valls Cuevas, J. M. \& Devaraj, N. K. SNAP-tag-reactive lipid anchors enable targeted and spatiotemporally controlled localization of proteins to phospholipid membranes. J. Am. Chem. Soc. 137, 4884-4887 (2015).

55. Budin, I. \& Devaraj, N. K. Membrane assembly driven by a biomimetic coupling reaction. J. Am. Chem. Soc. 134, 751-753 (2012).

56. Brea, R. J., Cole, C. M. \& Devaraj, N. K. In situ vesicle formation by native chemical ligation. Angew. Chem. Int. Ed. 53, 14102-14105 (2014)

57. Hardy, M. D. et al. Self-reproducing catalyst drives repeated phospholipid synthesis and membrane growth. Proc. Natl Acad. Sci. USA 112, 8187-8192 (2015).

58. Zhou, C. Y., Wu, H. \& Devaraj, N. K. Rapid access to phospholipid analogs using thiol-yne chemistry. Chem. Sci. 6, 4365-4372 (2015).

\section{Acknowledgements}

Financial support was provided by the National Science Foundation of China (21622103, 21571098 and 21671099) and the Natural Science Foundation of Jiangsu Province (BK20160022).

\section{Author contributions}

F.X., L.L., Q.W., D.Y. and Y.C. carried out the experimental work; T.-Y.S. and X.Z. carried out the computational work, F.X., L.L., J.J.L and J.Z. wrote the manuscript; J.Z., W.W., Y.L. and W.-Y.S. guided the research.

\section{Additional information}

Supplementary Information accompanies this paper at http://www.nature.com/ naturecommunications

Competing interests: The authors declare no competing financial interests.

Reprints and permission information is available online at http://npg.nature.com/ reprintsandpermissions/

How to cite this article: Xiong, F. et al. A bioinspired and biocompatible ortho-sulfiliminyl phenol synthesis. Nat. Commun. 8, 15912 doi: 10.1038/ncomms15912 (2017).

Publisher's note: Springer Nature remains neutral with regard to jurisdictional claims in published maps and institutional affiliations.

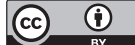

Open Access This article is licensed under a Creative Commons Attribution 4.0 International License, which permits use, sharing, adaptation, distribution and reproduction in any medium or format, as long as you give appropriate credit to the original author(s) and the source, provide a link to the Creative Commons license, and indicate if changes were made. The images or other third party material in this article are included in the article's Creative Commons license, unless indicated otherwise in a credit line to the material. If material is not included in the article's Creative Commons license and your intended use is not permitted by statutory regulation or exceeds the permitted use, you will need to obtain permission directly from the copyright holder. To view a copy of this license, visit http://creativecommons.org/ licenses/by/4.0/

(C) The Author(s) 2017 